УДК 621.791 .75

DOI: $10.25140 / 2411-5363-2019-4(18)-22-27$

Марина Агеева, Александр Размышляев

\title{
ВЛИЯНИЕ КОМБИНИРОВАННОГО МАГНИТНОГО ПОЛЯ НА ПРОИЗВОДИТЕЛЬНОСТЬ РАСПЛАВЛЕНИЯ ПРОВОЛОКИ ПРИ ДУГОВОЙ НАПЛАВКЕ
}

\begin{abstract}
Актуальность темы исследования. Применение управляющих продольного магнитного поля (ПрМП) и поперечного магнитного поля (ПоМП) при электродуговой наплавке и сварке проволокой под флюсом обеспечивает ряд технологических преимуществ. Применение ПрМП и ПоМП при дуговой наплавке и сварке проволокой под флюсом позволяет увеличить коэффичиент расплавления проволоки, управлять глубиной и площадью зоны проплавления основного металла, измельчать структурные составляющие наплавленного металла (шва).

Постановка проблемы. Повышение производительности процесса дуговой сварки и наплавки под флюсом определяется интенсифицированием процесса расплавления проволоки. Совместное влияние ПрМП и ПоМП, то есть комбинированное магнитное поле, позволит в большей степени увеличить коэффициент расплавления проволоки.

Анализ последних исследований и публикаций. В последних публикациях исследовано влияние ПрМП и ПоМП на коэффициент расплавления проволоки при дуговой сварке и наплавки под флюсом. Применение управляющих комбинированных магнитных полей при дуговой сварке исследовано для сварки неплавящимся электродом.

Выделение неисследованных частей общей проблемы. Практически нет работ, в которых бы изучалось совместное влияние ПрМП и ПоМП, то есть комбинированного магнитного поля (КМП) на коэффициент расплавления электродной проволоки при дуговой наплавке и сварке под флюсом.

Постановка задачи. Определение влияния комбинированного магнитного поля на коэффициент расплавления электродной проволоки при дуговой наплавке под слоем флюса.

Изложение основного материала. Сконструировано устройство для создания КМП. Исследовано распределение компонент индукции КМП, а также влияние КМП на коэффищиент расплавления электродной проволоки при дуговой наплавке под слоем флюса для ферромагнитных и неферромагнитных проволок.

Выводы в соответствии со статьей. Определены значения коэффициента расплавления проволок как ферромагнитных, так и неферромагнитных при дуговой наплавке под флюсом.

Ключевые слова: дуговая наплавка; комбинированное магнитное поле; индукция; коэффициент расплавления проволоки.

Рис.: 3. Библ.: 7.
\end{abstract}

Актуальность темы исследования. Применение управляющих продольного магнитного поля (ПрМП) и поперечного магнитного поля (ПоМП) при электродуговой наплавке и сварке проволокой под флюсом обеспечивает ряд технологических преимуществ, краткий обзор которых приведен в работах $[1,2]$. Применение ПрМП и ПоМП при дуговой наплавке и сварке проволокой под флюсом позволяет увеличить коэффициент расплавления проволоки, управлять глубиной и площадью зоны проплавления основного металла, измельчать структурные составляющие наплавленного металла (шва) [1-5].

Постановка проблемы. Повышение производительности процесса дуговой наплавки и сварки под флюсом определяется интенсифицированием процесса расплавления проволоки. Совместное влияние ПрМП и ПоМП, т.е. комбинированное магнитное поле позволит в большей степени увеличить коэффициент расплавления проволоки.

Анализ последних исследований и публикаций. Применение управляющих комбинированных магнитных полей при дуговой сварке отражено в работах [6; 7]. Однако эти данные относятся к сварке неплавящимся электродом. В работе [1] показано, что знакопеременное ПрМП частотой $f=50$ Гц обеспечивает повышение коэффициента расплавления проволоки $\left(\alpha_{p}\right)$ на $18 . .20 \%$, а постоянное ПрМП - на $30 \%$. С воздействием постоянного ПоМП при наплавке эффект повышения $\alpha_{p}$ составляет $27 \ldots 30 \%$, а при частоте 50 Гц эффект повышения $\alpha_{p}$ снижается до 0 [2].

Выделение неисследованных частей общей проблемы. Однако нет работ, в которых бы изучалось совместное влияние ПрМП и ПоМП, то есть комбинированного магнитного поля (КМП) на коэффициент расплавления электродной проволоки $\alpha_{p}$ при дуговой наплавке и сварке под флюсом. Это потребовало выполнения исследований, результаты которых изложены в данной работе.

(C) Агєєва М. В., Размишляєв О. Д., 2019 
TECHNICAL SCIENCES AND TECHNOLOGIES

Постановка задания (цель статьи). Целью настоящей работы является определение влияния комбинированного магнитного поля на коэффициент расплавления электродной проволоки при дуговой наплавке под слоем флюса.

Изложение основного материала. Для создания КМП использовали устройства, генерирующие отдельно ПрМП и ПоМП. Схема и конструкция устройства, генерирующего КМП, приведены на рис. 1.

Для создания ПрМП в устройстве, представленном на рис. 1, использовалась четырехслойная обмотка 1 с числом витков 144. Обмотка выполнена из медной проволоки диаметром 2 мм, которая изолирована от ферросердечника 2 с помощью изолятора 3. Ферросердечник 2 с наружным диаметром 52 мм и внутренним диаметром 24 мм изготовлен из стали типа Ст.3. Ферросердечник имеет внизу буртик 4 для удержания обмотки 1. Соленоид крепился на автомат типа АДС-1002 с помощью болтовых соединений. Сердечник имел внутри отверстие, в котором проходил мундштук 5 с токоподводящими губками 6. Внутри мундштука проходила электродная проволока 7.

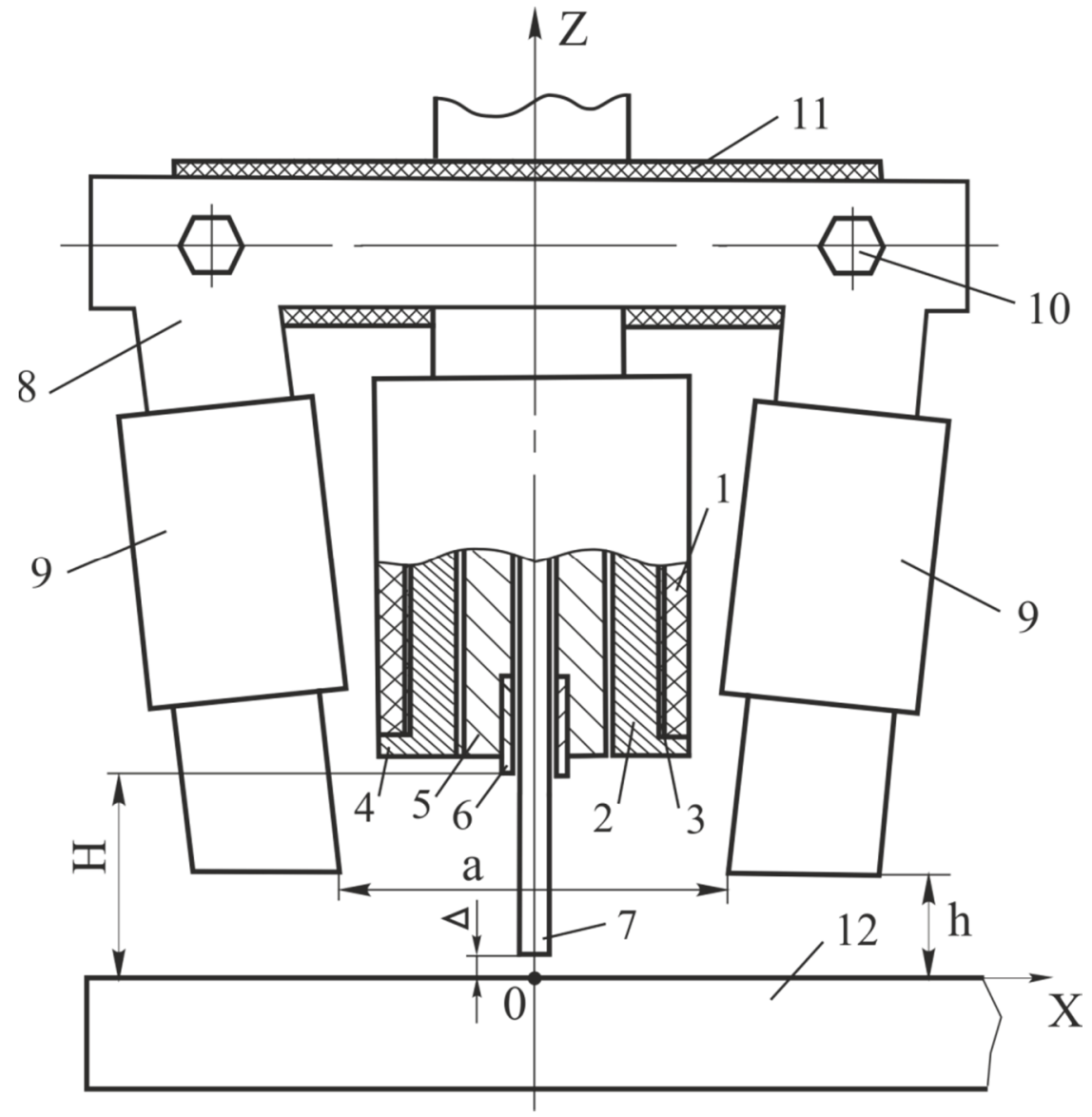

Рис. 1. Схема устройства, генерирующего КМП:

1 -четырехслойная обмотка, 2 - ферросердечник, 3-изолятор, 4-буртик, 5 -мундштук,

6 - токопроводящче губки, 7 - электродная проволока, 8 -магнитопровод,

9 - наклонные участки с обмоткой, 10 - болты, 11 - изолятор, 12 - пластина

Для создания ПоМП в устройстве, представленном на рис. 1, используется магнитопровод 8 , состоящий из трёх участков. Два наклонных участка, на которых размещены обмотки 9, а также горизонтальный участок, соединенный с наклонными с помощью болтовых соединений 10. Магнитопровод собран из пластин электротехнической стали толщиной 0,5 мм. Сечение набора $30 \times 20$ мм. Две обмотки 9 выполнены двухслойно из медного изолированного провода диаметром 2 мм. Количество витков в одной обмотке составляло $\mathrm{W}=70$. 
TECHNICAL SCIENCES AND TECHNOLOGIES

Соленоид с ферросердечником, генерирующий ПрМП, и устройство, генерирующее ПоМП, крепили на сварочный автомат типа АДС-1002. При этом магнитопровод 8 изолировался от автомата изолятором 11. Автомат позволял изменять параметр Н (вылет электрода), т.е. расстояние между токоподводящими губками 6 и пластиной 12 , а также $\mathrm{h}$ - расстояние от торцов магнитопровода 8 до поверхности пластины 12 . Конструкция устройства позволяла изменять расстояние между нижними участками магнитопровода у торца электрода (параметр а). Электродная проволока 7 проходила через токоподводящие мундштук 5 и губки 6.

На рис. 1 приведена также система координат, принятая для исследования магнитного поля. При этом начало координат располагалось на поверхности пластины под осью электрода. Для изучения конфигурации КМП в зоне капли и дуги проводились измерения компоненты индукции вдоль оси $\mathrm{OX}\left(\mathrm{B}_{x}\right)$ и продольной $\left(\mathrm{B}_{z}\right)$ компоненты индукции вдоль оси OZ. Во всех экспериментах сохраняли постоянными параметры $\mathrm{I}_{\kappa}=45 \mathrm{~A} ; \mathrm{H}=35$ мм; $\mathrm{a}=70$ мм; $\mathrm{h}=25$ мм. Катушки устройств, генерирующих ПрМП и ПоМП, были включены последовательно. Во всех экспериментах через катушки пропускали переменный ток $\mathrm{I}_{\kappa}=20$ А частотой $f=5$ Гц от генератора прямоугольных импульсов, конструкция которого описана в работе [2].

Измерения компонент индукции $\mathrm{B}_{x}$ и $\mathrm{B}_{z}$ проводили универсальным тесламетром типа 43205 с датчиком Холла, имевшим измерительную базу 0,9×0,9 мм. Измерения проводились при $\mathrm{Z}=0$; $\mathrm{Y}=0$ : вдоль оси $\mathrm{OX}$ через 5 мм. В исследованиях использовалась ферромагнитная сварочная проволока Св-08ГА диаметром 4 мм, а в качестве основного металла - пластины из немагнитной стали Ст.12Х18Н10Т толщиной $10 \ldots 20$ мм.

Исследовали распределение компонент индукции $\mathrm{B}_{x}$ и $\mathrm{B}_{z}$, которые генерирует каждое составляющее КМП, то есть раздельно ПрМП и ПоМП, а также при их совместном согласованном действии.
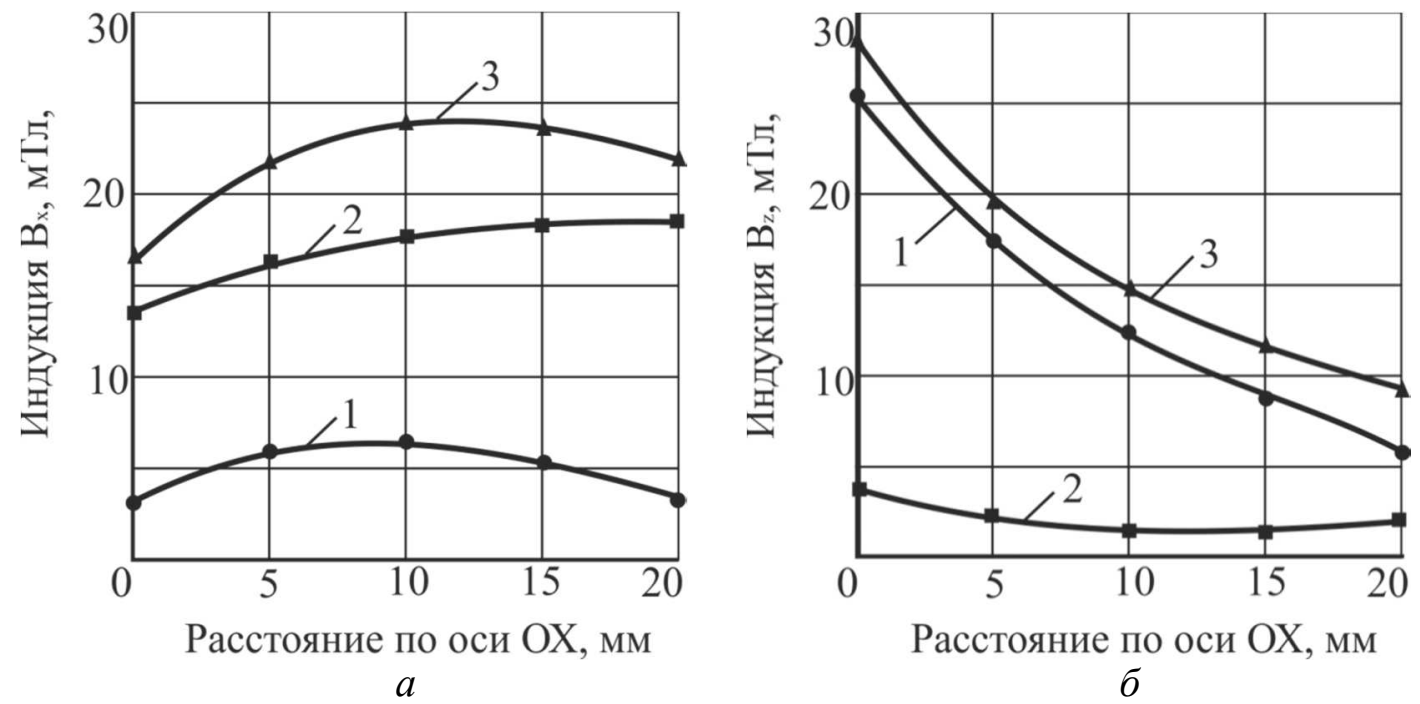

Рис. 2. Распределение компонент индукиии $B_{x}\left(\right.$ a) и $B_{z}$ (б) вдоль оси $O X$ при воздействии КМП $\left(I_{\kappa}=45 \mathrm{~A} ; H=35 \mathrm{мм} ; a=70 \mathrm{мм} ; h=25 \mathrm{мм} ; Z=0 ; Y=0\right)$ : $1-\Pi р М \Pi ; 2-\Pi о М \Pi ; 3-К М \Pi$

Данные измерений показали, что компонента индукции $\mathrm{B}_{x}$ значительно больше при воздействии ПоМП, чем при воздействии ПрМП (рис. $2, a$ - кривые 1,2 ). Компонента индукции $\mathrm{B}_{z}$ значительно больше при воздействии ПрМП (рис. 2, $\sigma$ - кривые 1, 2). Таким образом, каждое из составляющих КМП (ПрМП и ПоМП) генерирует определённый уровень одной из компонент индукции $\mathrm{B}_{x}$ или $\mathrm{B}_{z}$, а при совместном действии ПрМП и ПоМП, эти компоненты индукции суммируются (рис. 2, $a$ и $\sigma$ - кривые 3 ). 
TECHNICAL SCIENCES AND TECHNOLOGIES

Исследовали коэффициент расплавления электродного металла $\alpha_{p}$ при воздействии КМП. Эксперименты выполнялись с использованием знакопеременного КМП частотой $f=5$ Гц, поскольку при этом обеспечивается хорошее формирование наплавленного валика [1]. Выполняли экспериментальные наплавки автоматом АДС-1002 с независимой от напряжения дуги скоростью подачи электрода от выпрямителя ВДУ-1201 (с падающей внешней характеристикой на обратной полярности) под флюсом АН-348А. Во всех экспериментах параметры режима наплавки без воздействия магнитного поля устанавливались предварительно по стрелочным приборам, и они составляли при диаметре проволоки $\mathrm{d}_{\ni}=4$ мм: $I_{H}=500 \ldots 520 \mathrm{~A} ; U_{\partial}=28 \ldots 30 \mathrm{~B}$. Скорость наплавки $V_{H}=30$ м/ч. Продолжительность процесса наплавки составляла не менее 30 с. Выполняли $3 \ldots 5$ наплавок на каждом режиме. Параметры $\mathrm{H}, \mathrm{a}, \mathrm{I}_{\kappa}$ и $\mathrm{h}$ сохраняли постоянными, соответственно $\mathrm{H}=35$ мм; $\mathrm{a}=70$ мм; $\mathrm{I}_{\kappa}=45$ А. Во всех экспериментах использовали ферромагнитную проволоку Св-08ГА диаметром 4 мм и пластины из немагнитной стали Ст.12Х18Н10Т.

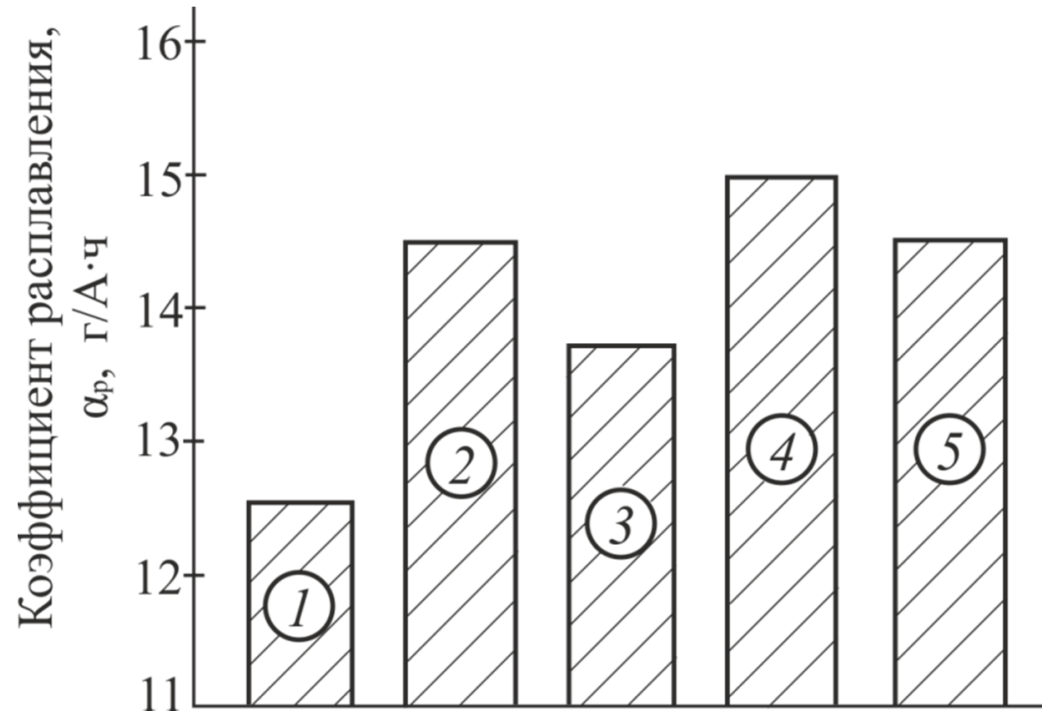

Рис. 3. Коэффиџиент расплавления электродного металла $\alpha_{p}$ при наплавке под флюсом:

1 - без воздействия магнитного поля; 2 - с воздействием ПРМП; 3 - с воздействием ПОМП;

4 - с воздействием КМП; 5 - с воздействием КМП (проволока 06Х18Н9Т диаметром 4 мм)

Анализируя результаты, полученные в экспериментах с воздействием КМП, ПрМП и ПоМП, можно отметить, что при воздействии одного ПрМП с индукцией $\mathrm{B}_{z}=25$ мТл, повышение коэффициента расплавления электродного металла $\alpha_{p}$ составило около $18 \%$ (14,5 г/А·ч) (рис. 3, столбик 2). При воздействии ПоМП с величиной компоненты индукции $\mathrm{B}_{x}=15$ мТл, повышение $\alpha_{p}$ составило $10 \%$ (13,7 г/А·ч) (рис. 3 - столбик 3 ). При воздействии КМП значения $\alpha_{p}$ было несколько больше, чем в двух предыдущих случаях, и оно составило 15 г/А·ч (рис. 3, столбик 4, повышение $\alpha_{p}$ на $21 \%$ ).

Таким образом, при воздействии КМП уровень коэффициента расплавления электродной проволоки $\alpha_{p}$ выше по отношению к вариантам, когда отдельно использовалось ПрМП или ПоМП.

Выполняли также наплавки проволокой Св-06Х18Н9Т (немагнитной) диаметром 4 мм с воздействием КМП на том же режиме, что и при наплавке проволокой Св-08ГА. Получено приращение $\alpha_{p}$ от 13 г/А·ч (без воздействия КМП) до 14,5 г/А·ч при воздействии КМП (рис. 3, столбик 5), то есть на 11,3\% (при уровне $\mathrm{B}_{x}=15$ мТл). Поскольку ПрМП не повышает $\alpha_{p}$ при наплавке немагнитными проволоками [1], то этот эффект приращения $\alpha_{p}$ при наплавке с воздействием КМП обусловлен воздействием компоненты $\mathrm{B}_{\mathrm{x}}$ (в основном от ПоМП). Таким образом, КМП целесообразно применять при наплавке не только ферромагнитными проволоками (Св-08ГА), но и неферромагнитными проволоками (Св-06Х18Н9T). 
TECHNICAL SCIENCES AND TECHNOLOGIES

Выводы в соответствии со статьёй. При дуговой наплавке под слоем флюса с воздействием внешних магнитных полей частотой 5 Гц повышение коэффициента расплавления $\left(\alpha_{p}\right)$ проволоки Св-08ГА составило 18 \% при воздействии ПРМП и $10 \%$ при воздействии ПОМП, а при воздействии КМП (комбинации ПрМП и ПоМП) - $21 \%$. При наплавке немагнитной проволокой (Св-06Х18Н9Т) воздействие КМП обеспечило повышение $\alpha_{p}$ на $11,3 \%$.

При дуговой наплавке с целью повышения коэффициента расплавления $\alpha_{p}$ использование КМП целесообразно для проволок как ферромагнитных, так и неферромагнитных.

\section{Список использованных источников}

1. Размышляев А. Д., Миронова М. В. Магнитное управление формированием валиков и швов при дуговой наплавке и сварке: монография. Мариуполь: Изд-во ПГТУ, 2009. 242 с.

2. Размышляев А. Д., Выдмыш П. А., Агеева М. В. Автоматическая электродуговая сварка под флюсом с воздействием внешнего магнитного поля: монография. Мариуполь: Изд-во ПГТУ, 2017. 209 с.

3. Razmyshlyaev A. D., Mironova M. V. Efficiency of the process of penetration of the parent metal in submerged-arc surfacing. Welding International. 2012. Vol. 26, № 11. P. 862-866.

4. Boldyrev A. M., Birzhev V. A., Chernykh A. V. Special features of melting electrode metal when welding in an external longitudinal magnetic field. Welding International. 1992. Vol. 6, № 10. P. 812-814.

5. Boldyrev A. M., Birzhev V. A., Martynenko A. I. Examination of the effect of the alternating axial magnetic field on the process of melting of electrode wire. Welding International. 2009. Vol. 23, № 3. P. 223-224.

6. Рыжов Р. Н. Применение комбинированных электромагнитных воздействий для улучшения качества швов при сварке неплавящимся электродом. Автоматическая сварка. 2005. № 7. C. $59-61$.

7. Рижов Р. М., Кузнецов В. Д. Магнітне керування якістю зварних з'єднань. Київ: Екотехнологія, 2010. 284 с.

\section{References}

1. Razmyshlyaev, A. D., Mironova, M. V. (2009). Magnitnoe upravlenie formirovaniem valikov $i$ shvov pri dugovoi naplavke i svarke [Magnetic control of formation of beads and welds in arc surfacing and welding]. Mariupol: PGTU [in Russian].

2. Razmyshlyaev, A. D., Vydmysh P.A., Ahieieva M.V. (2017). Avtomaticheskaia elektrodugovaia svarka pod fliusom s vozdeistviem vneshnego magnitnogo polia [Automatic submerged arc welding with the act of external magnetic field]. Mariupol: PGTU [in Russian].

3. Razmyshlyaev A.D., Mironova M.V. (2012). Efficiency of the process of penetration of the parent metal in submerged-arc surfacing. Welding International, 26, 11, 862-866.

4. Boldyrev A. M., Birzhev V. A., Chernykh A. V. (1992) Special features of melting electrode metal when welding in an external longitudinal magnetic field. Welding International, 6, 10, 812-814.

5. Boldyrev A. M., Birzhev V. A., Martynenko A. I. (2009). Examination of the effect of the alternating axial magnetic field on the process of melting of electrode wire. Welding International, 23, 3, 22-224.

6. Ryzhov, R. N. (2005). Primenenie kombinirovannykh elektromagnitnykh vozdeistvii dlia uluchsheniia kachestva shvov pri svarke neplaviashchimsia elektrodom [The use of combined electromagnetic effects for improving the quality of welds at welding with a non-consumable electrode]. Avtomaticheskaia svarka - The Paton Welding J., 7, 59-61 [in Russian].

7. Ryzhov, R. M., Kuznetsov, V. D. (2010). Mahnitne keruvannia yakistiu zvarnykh ziednan [Magnetic control of welded joints quality]. Kyiv: Ekotekhnolohiia [in Ukrainian].

$U D C 621.791 .75$

Marina Ahieieva, Aleksandr Razmyshlyaev

\section{THE COMBINED MAGNETIC FIELD INFLUENCE ON THE WELD MELTING PRODUCTIVITY AT ARC SURFACING}

Urgency of the research. The use of longitudinal magnetic field (LMF) and transverse magnetic field (TMF) at submerged arc surfacing and welding provides a number of technological advantages. The use of LMF and TMF at submerged 


\section{TECHNICAL SCIENCES AND TECHNOLOGIES}

arc surfacing and welding allows to increase the wire melting coefficient, control the depth and area of the penetration zone of the base metal, grind the structural components of the surfaced metal (weld).

Target setting. The increase of productivity of the submerged arc welding and surfacing process is determined by the intensification of wire melting process. The combined effect of LMF and TMF, i.e. combined magnetic field will allow to increase the wire melting coefficient to a greater extent.

Actual scientific researches and issues analysis. In recent publications, the effect of LMF and TMF on the wire melting coefficient at submerged arc welding and surfacing has been investigated. The use of combined magnetic fields in arc welding has been investigated for non-consumable electrode welding.

Uninvestigated parts of general matters defining. There are practically no works that would study the combined effect of LMF and TMF, i.e., a combined magnetic field (CMF) on the electrode wire melting coefficient at submerged arc surfacing and welding.

The research objective. Determination of the combined magnetic field influence on the electrode wire melting coefficient at submerged arc surfacing.

The statement of basic materials. Designed a device for creating the CMF. The distribution of the CMF induction components, as well as the CMF influence on the electrode wire melting coefficient at submerged arc surfacing for ferromagnetic and non-ferromagnetic wires is studied.

Conclusions. The values of the wires melting coefficient, both ferromagnetic and non-ferromagnetic, are determined for submerged arc surfacing.

Keywords: arc surfacing; combined magnetic field; induction; wire fusion coefficient.

Fig.: 3. References: 7.

Агєєва Марина Володимирівна - кандидат технічних наук, доцент, доцент кафедри обладнання і технологій зварювального виробництва, Донбаська державна машинобудівна академія (вул. Академічна, 72, м. Краматорськ, 84300 Україна)

Ahieieva Marina - PhD in Technical science, Associate Professor, Associate Professor of equipment and technology of welding production department, Donbass state engineering academy (72 Akademicheska Str., 84300 Kramatorsk, Ukraine).

E-mail: maryna_ah@ukr.net

ORCID: https://orcid.org/0000-0001-8275-6781

SCOPUS Author ID: 57197921565

Размишлясв Олександр Денисович - доктор технічних наук, професор, професор кафедри автоматизації та механізації зварювального виробництва, ДВНЗ «Приазовський державний технічний університет» (вул. Університетська, 7, м. Маріуполь, 87555, Україна).

Razmyshlyaev Aleksandr - Doctor in Technical science, Professor, Professor of automation and mechanization of welding production department, State Higher Educational Institution «Pryazovskyi state technical university» (7 Universitetska Str, 87555 Mariupol, Ukraine).

E-mail: razmyshlyaev@rambler.ru

ORCID: https://orcid.org/0000-0001-6616-7717

SCOPUS Author ID: 6602501672 